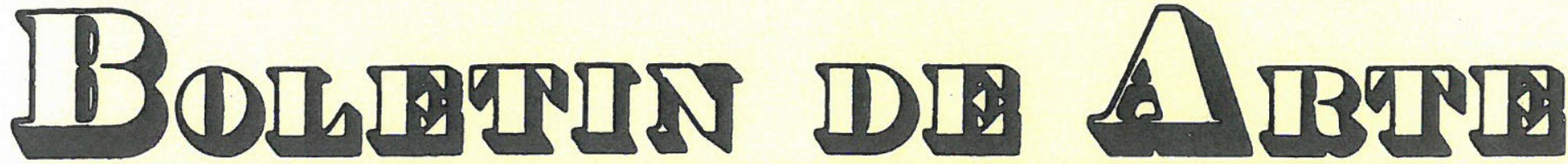

Núm. 20

1999

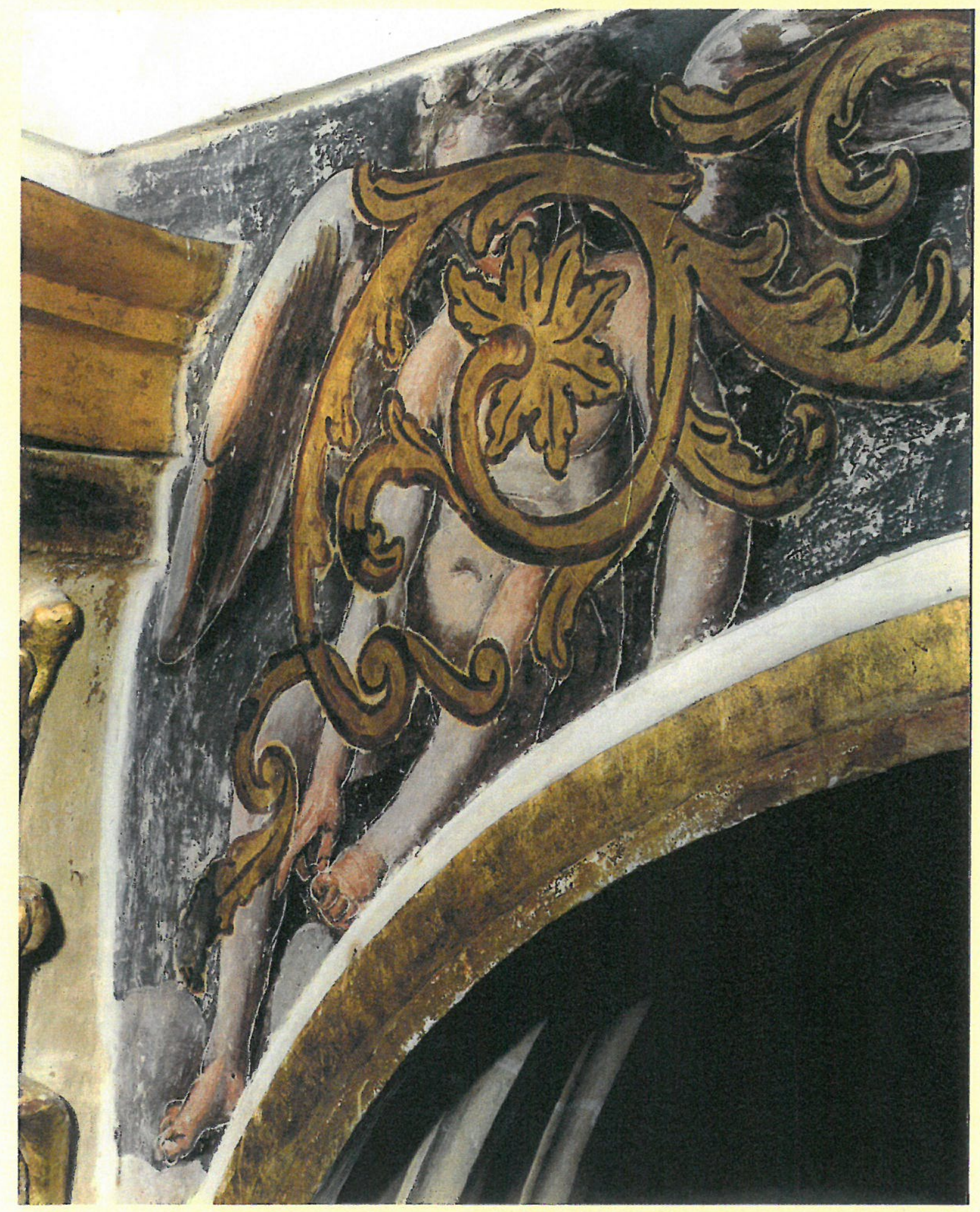

UNIVERSIDAD DE MALAGA

DEPARTAMENTO DE HISTORIA DEL ARTE 


\section{ARTículos}

UNA TIPOLOGÍA URBANA: LA CALLE DE CABALLEROS EN ESPAÑA, por Antonio Bonet Correa

TEATROS DE NATURALEZA: ESCENARIOS PARA LOS DIOSES. ARTIFICIOS Y OTROS INGENIOS EN LOS JARDINES ESPAÑOLES DEL RENACIMIENTO AL BARROCO, por Carmen González Román

UNA LECTURA SIMBÓLICA DEL PLATERESCO SEGÚN EL PSICOANÁLISIS DE LA PERCEPCIÓN DE EHRENZWEIG, por César García Alvarez

EL MUNDO AL REVÉS. LECTURAS ICONOGRÁFICAS SOBRE UN GRABADO DE ANTON WIERIX CONTRA EL DOMINIO DE FELIPE, por Vicente Pla Vivas

SÍMBOLOS Y HERÁLDICA EN LOS EXPEDIENTES DE ÓRDENES MILITARES EN MURCIA DURANTE EL SIGLO XVI, por Francisco José García Pérezy Juan Hernández Franco

ESCULTORES Y PINTORES DEL CÍRCULO ANTEQUERANO DEL SIGLO XVI. APORTACIONES DOCUMENTALES, por José Escalante Jiménez

EL VENERABLE FERNANDO CONTRERAS, UN SANTO PARA LA CATEDRAL DE SEVILLA, por Fernando Quiles García

DIVERSIDAD PROFESIONAL EN LA CREACIÓN DEL RETABLO. EL CÁDIZ BARROCO, por Lorenzo Alonso de la Sierra Fernández

FIESTA Y CEREMONIAL DE LAS CORTES DE GÉNOVA Y MADRID. LLEGADA Y CELEBRACIÓN DEL MATRIMONIO DE LA NUEVA PRINCESA DE ASTURIAS Ma LUISA DE PARMA EN 1765, por Laura García Sánchez

LA REAL ACADEMIA DE SAN CARLOS: NEOCOLONIA ARTÍSTICA, por Tania García Lescaille 


\title{
EL VENERABLE FERNANDO CONTRERAS, UN SANTO PARA LA CATE- DRAL DE SEVILLA
}

\section{Fernando Quiles García}

\begin{abstract}
El proceso de canonización del Venerable Fernando Contreras, promovido por la Catedral de Sevilla e iniciado hacia 1631, muestra la gran influencia que tuvo la creación de santos en la configuración del arte barroco en el mundo católico y, por ende, el enorme protagonismo de la Corte Pontificia en la toma de decisiones sobre la producción artística de los talleres provinciales.
\end{abstract}

Señores dadnos por Dios pues que venimos a vos. Habed compasión de nos. Que Dios os lo a de pagar. Por dios ayudad, por dios ayudad, a estos captivos de Gibraltar.

En 1588 el papa Sixto V reanudó la práctica de las canonizaciones que se había interrumpido a principios de siglo. Era la consecuencia lógica del incremento experimentado por el culto a los santos con el concilio de Trento. Ello tuvo su trascendencia en materia artística, con la creación de una nueva iconografía y la revitalización de la centralidad romana. De la lectura de los diversos expedientes de canonización promovidos por la Catedral de Sevilla, a los que he tenido acceso, deduzco que la Corte Pontificia, a la que se eleva toda la información obtenida sobre los distintos personajes a los que se quiere canonizar, ejerció un control directo sobre las imágenes que se creaban en torno a éstos. Sobre esto último ofrece curiosas noticias la documentación conservada, con claros indicios de que el Colegio Pontificio mantuvo un rígido control sobre la nueva iconografía, cuya definición cuidó y dejó en manos de los talleres romanos para que allí fuera modelada. Este hecho acentuó aún más la posición centralizada de capital italiana en un Imperio Católico. Pese a su importancia, la Iglesia sevillana ocupa un lugar periférico, lo mismo que le ocurre a los talleres artísticos que producen el arte religioso que demanda.

Éstas y otras cuestiones aparecen referidas, cuando no sugeridas, en la documentación de la causa del venerable Fernando de Contreras que se guarda en la Catedral sevillana. Veremos cómo se produce el contacto entre el clero sevillano y 


\section{Fernando Quiles}

el romano a propósito de este santo varón; siendo de destacar el protagonismo de los promotores pontificios que integraban la Sacra Congregación de Ritos y cómo hicieron valer su indiscutible prelacía para obtener el control de la iconografía de Contreras, aunque fuera compuesta sobre modelos antiguos en Sevilla.

La Catedral de Sevilla quiso elevar a los altares a Fernando de Contreras (Sevilla, 1470-1548), un sacerdote virtuoso entregado en cuerpo y alma a la redención de cautivos cristianos en Berbería, satisfaciendo asimismo los anhelos de una ciudad que apreciaba esa generosa labor de la que se hicieron eco varias generaciones de sevillanos y, sobre todo, por el cabildo catedralicio, del que había formado parte. La tramitación del proceso de canonización no fue más que un intento de ratificar lo que en la ciudad se sentía, que fue expresado por el abad Gordillo de esta manera: no es hazer santo a uno llamarle sancto sino solo estimarlo y reconocer en él las virtudes que tuvo que le hizieron digno de semejante appellido estimatorio y este le da el pueblo ${ }^{1}$. Contreras merecía el reconocimiento pontificio de una dignidad que le otorgaba la ciudadanía, y para la Iglesia era algo más que eso, era crear el mito del paladín de la causa contrarreformista, algo que se había conseguido con San Fernando. Y, aunque no hubo fortuna, se intentó, en un complejo y lento proceso que exigió un despliegue humano y un esfuerzo económico sólo posible para una institución con los medios de la Catedral sevillana.

La difusa documentación del proceso está compuesta por los textos oficiales, que abundan en expresiones abstrusas, y otros, más personales y directos, que arrojan una luz rasante más vívida. De entre la enorme cantidad de datos que aportan sobre Contreras, merecen ser destacados los que ilustran cómo fue concebida su imagen de bienaventurado y sobre todo el papel que jugaron los artistas y las iglesias sevillana y romana en su definición. Por ello, aunque no produjera los frutos deseados, sirvió de estímulo a la creatividad, al conectar los talleres artísticos sevillanos y romanos. En este sentido, hay que dar la razón a Emile Mâle, quien hace unas décadas reconoció el endeudamiento del arte barroco con las canonizaciones ${ }^{2}$.

Para obtener de la Sagrada Congregación de Ritos, en Roma, la canonización de un personaje de las características de Contreras, era preciso mucha paciencia, mucho dinero y grandes dotes diplomáticas, sin olvidar la indispensable protección de algunos de los cardenales de la corte pontificia. De todo ello estaba sobrada la Catedral de Sevilla. La Iglesia Metropolitana anduvo ocupada durante gran parte del siglo XVII en varias canonizaciones, de las que sólo una parece que alcanzó el fin pretendido: la de Fernando III $^{3}$ : corto resultado, quizás, para el entusiasmo que se puso al menos

\footnotetext{
${ }^{1}$ A lo que añadiría: assi vemos q al sr. rey don frdo. $3^{\circ}$ siempre se le ha llamado por comun opinion el rey sto. y lo dize el escrito q comienza: Hercules me ediffico... Idem. Fol. 163.

2 MÂLE, Emile: El Barroco. El arte religioso del siglo XVII. Italia, Francia, España, Flandes. Madrid, Encuentro, 1985, pág. 109.

${ }^{3}$ A la que he dedicado un artículo: "En los cimientos de los Iglesia sevillana: Fernando III rey y santo", en prensa.
} 
en tres proyectos. Es posible que se llegara tarde, pues la fiebre canonizadora remitía por momentos. En el primer cuarto del siglo XVII hubo prisas por crear santos, por la vía de urgencia fueron canonizados San Carlos Borromeo (proceso, 1604-1610) y Santa Teresa, San Ignacio, San Felipe Neri y San Francisco Javier (estos cuatro en 1622). Apenas apagadas las luminarias del magno acto en el que alcanzaron la santidad los cuatro grandes reformadores de la Iglesia católica, de los que tres eran españoles, la Catedral activó el proceso de canonización de Fernando III y poco después los de Fernando de Contreras y Sor Francisca Dorotea. Sin embargo, después de este gran acto final que formalizaba el panteón católico, se apaciguaron los ánimos y en adelante las beatificaciones y canonizaciones marcharían a un ritmo más lento.

El Venerable Contreras entró en la cadena algo más tarde, en un envite que iba a ser largo y disputado por tratarse del símbolo de la Catedral y no representar a ninguna de las grandes órdenes religiosas. En efecto, iniciado en 1631 se alargó más de un siglo, pues todavía en el último cuarto del XVIII está coleando sin la seguridad de llegar a buen término.

La idea de beatificar y canonizar a Fernando de Contreras partió del cuerpo capitular sevillano, al distinguirle como miembro ejemplar y como pieza importante en su empíreo particular. Todo empezó en 1631. Durante décadas el proceso fue llevado a la par que el de Sor Francisca Dorotea, entrando juntos, en 1642, en la Congregación de Ritos 4 .

Despejada cualquier duda en el seno de la Iglesia sevillana, acerca de la importancia de este sacerdote, se iniciaron los trámites ante la curia pontifica con el apoyo de los agentes sevillanos destacados en Roma. Es posible que en sus inicios interviniera el inteligente y combativo canónigo don Bernardo del Toro e incluso don Juan de Córdoba, sin embargo, destacaría la figura del procurador de la causa, en una etapa algo más adelantada, don Bernardo Gallo. A él le correspondió activar el proceso imprimiéndole cierta celeridad y allanado importantes obstáculos. En Sevilla tuvo la colaboración del eficiente don Juan de Loaysa, nombrado por el cabildo para dirigir el trabajo de acopio de la documentación. Pero ni éste ni los que le sucedieron a lo largo de todo el siglo XVIII consiguieron levantar la losa que, con el éxito de la causa de Fernando III, cayó sobre ésta y la causa de Sor Francisca Dorotea. Ni siquiera la protección de los cardenales Barberini lograron rendir al inflexible tribunal romano.

Bajo los mandatos de don Luis de Salcedo y don Francisco de Solís, cobró nueva vida el proceso ${ }^{5}$. Por entonces Contreras era tenido como un símbolo y había

\footnotetext{
${ }^{4}$ A[rchivo de la] C[atedral de] S[evilla]. VIII. Varios. Leg. 42 (1). 1642. "Instrvcciones para los processo de los venerables siervos de Dios Fernando de Contreras y Sor. Francisca Dorothea". La causa de beatificación canonización fue introducida, en dicho año, en la Congregación de los Sagrados Ritos, por comisión signada de mano de Urbano VIII.

${ }^{5}$ ACS. VIII. Leg. 48 (7). Autos de la causa de Beatificación y canonización de Contreras. En 1731 hubo Letras Remisoriales, bajo la procuraduría de don Diego Antonio del Campo y la mediación de don Gabriel de Torres, don José Manuel de Céspedes, don Juan Cornejo y don Joaquín de la Pradilla, siendo expedidas el 24 de julio.
} 


\section{Fernando Quiles}

entrado en el repertorio iconográfico del arte local. Bajo el gobierno de Solís se incrementó notablemente el esfuerzo para alcanzar la canonización. En alguna medida debió incidir la relación del prelado con la corte pontificia, de cuya Sacra Congregación de Ritos llegó a formar parte ${ }^{6}$. Ni aún así fue posible enaltecer a Contreras.

\section{TRAS LOS PASOS DE CONTRERAS}

Ni siquiera al comienzo del proceso, en el expediente informativo de 1631, pudo atestiguar nadie que conociera a Contreras en vida. Así quedó de manifiesto en las respectivas respuestas, aunque ninguno de los entrevistados escatimó halagos sobre su comportamiento. El grupo de los llamados a responder al cuestionario confeccionado para catalogar debidamente a Contreras era excepcional, con algunas de las más importantes personalidades del mundo religioso sevillano de la época. Basta con recordar los nombre del licenciado Sebastián Vicente Villegas ${ }^{7}$, uno de los más relevantes maestros de ceremonias de la Catedral, Alonso Sánchez Gordillo ${ }^{8}$, abad mayor de la Universidad de Beneficiados, el polígrafo Rodrigo Caro ${ }^{9}$ o el eminente jesuita Juan de Pineda, autor de un Memorial sobre la santidad de Fernando III $^{10}$. Menos importante, si bien por desconocimiento de su quehacer, fue el pintor Pedro Calderón de Acedo, hermano del aparejador mayor del hospital de la Sangre, Manuel Acedo" ${ }^{11}$.

La causa entró de lleno en la Congregación de Ritos bajo el pontificado de Urbano VIII (1623-1644), un Papa de gran predicamento en el seno de la Iglesia sevillana. No en balde este cabildo se encontraba bajo la protección del sobrino del Pontífice, Francisco Barberini, con quien mantenía relación epistolar. De entonces data una segunda fase en la cumplimentación de la memoria, las Instrucciones $(1642)^{12}$.

Transcurren los años y el proceso no acaba de rendir los resultados apetecidos. El arribo a buen puerto de la causa de San Fernando (1671) evidenció el atasco en que se había detenido la de Contreras. Daba la impresión de que el esfuerzo realizado desde los años treinta había sido baldío, hablándose del olvido como sepultura del

\footnotetext{
6 MOLI FRIGOLA, Montserrat: "Sevilla en Roma. Los viajes del cardenal Francisco de Solís en 1769 y 1774-1775", Archivo Hispalense, n 224, Sevilla, Diputación de Sevilla, 1990, págs. 67-84.

8 ACS. VIII. Leg. 43 (2). "Informaciones...", op. cit. Testigo 22, fol. 95v.

8 Idem. Testigo 25 , fol. $107 \mathrm{v}$.

9 Idem. Fol. $118 \mathrm{r}$.

${ }^{10}$ Idem. Fol. 120v. El título completo del texto apologético es: Memorial de la excelente santidad y heróycas virtudes del Señor Rey Don Fernando, Tercero de este nombre, Primero de Castilla y de León. Sevilla,

${ }^{11}$ Idem. Fol. 76. 31-X-1631. Pedro Calderón [firma: de Azedo] pintor, de 65 años, vecino de la collación de San Andrés. No le conoció pero había oído de él.

12 ACS. VIII. Varios. Leg. 42 (1). 1642. "Instrvcciones para los processo de los venerables siervos de Dios Fernando de Contreras y Sor. Francisca Dorothea".
} 
expediente ${ }^{13}$. De ahí que se reabriera en a principios de los setenta con renovados bríos, dejándolo en manos de un trío de excepción, formado por los canónigos don Luis Federigui, don Bernardo de Estrada y don Juan de Loaysa, aunque antes de acabar la década la responsabilidad recaería plenamente sobre el último, uno de los más cultivados personajes de la época ${ }^{14}$. Éste conocía las más importantes bibliotecas de la ciudad y mantenía buenas relaciones con la élite cultural sevillana. Además la experiencia al frente del archivo de la Catedral le dio suficiencia en el manejo de las fuentes documentales. Todo ello, en suma, le presentaba como la persona idónea para cumplimentar la información que en Roma necesitaban para conocer a Fernando de Contreras $^{15}$. Ello coincide con una etapa de relativa tranquilidad en las aguas del Estrecho de Gibraltar que permitió visitar el Magreb para recabar noticias esenciales para la defensa del personaje. Precisamente, ésta fue una de las mayores novedades de esta hora del proceso, la visita a la región africana en la que había efectuado Fernando de Contreras las labores que le señalaron como bienaventurado y digno de canonización. El capitán Juan Mariño de Crestelo fue el arriesgado emisario que se trasladó a la inquietante región norteafricana para completar un cuestionario que se le había proporcionado, con las respuestas de los naturales del lugar con más edad y que habían tenido noticias claras del abnegado comportamiento del religioso ${ }^{16}$.

Por lo demás, Loaysa dirigió sus investigaciones a todos aquellos lugares donde había estado el Venerable, no despreciando indicio alguno que le pusiera sobre

13 [Ve. Contreras]. Leyeronse los autos de 25 de Agosto de 1636, de 16 de Marzo de 1638, de 28 de Julio de 1645, de 30 de Junio de 1656, y ultimamente el de 9 de Febrero de 1657, los mas en orden a que se solicite la Beatificacion del V. Sacerdote Ferdo. de Contreras; y deseando el Cab ${ }^{\circ}$ retraer esta causa del oluido, en que parece se auia sepultado, y proseguir la diligencias ${ }^{*}$ [* interpuestas] para conseguir el rotulo nombro a los SSes. Don Luis Federigui Arc ${ }^{\circ}$ de Carmona y Can ${ }^{\circ}$ Coadjutor, Don Berdo. de Estrada Can ${ }^{\circ}$ y Don Ju de Loaysa Rac para q asi en esta ciudad de Seuilla [Margen: Diputon. para su Beatificacion], como en la de Roma por medio de sus agentes especialmte por el Ju'Zenzano, como mas inteligente en estas materias reconoscan y se informen del estado desta solicitud, y tambien del sitio que a este singula Vaon seruia de pobre y humilde habitacion, y sobre ambos puntos refieran. ACS. Sec. I. Secretaría. Autos Capitulares. Lib. 71. 1671-1672, 1672, fol. 85. 14-XI.

${ }_{14}$ Este dia los ssres. de la diputacion de los Veners. sieruos de Dios Fernando de contreras y Madre Francisca Dorotea: dieron quenta; como auiendose retardado el empesar las probanças desta causas por varios accidentes, y hallarse oy el sr. Can ${ }^{\circ}$ D. Mateo coello, a quien su sria. tiene nombrado, por procurador de ellas, mui embaraçado, por cuia causa se a excusado de usar del poder, a parecido que siendo el cab ${ }^{\circ}$ seruido se le dé y nombre por procurador de ambas al sr. $R^{\circ}$. D. Juan de loaysa, que con el celo, y deuocion, que assiste se espera las adelante: y auiendo oydo dha proposssission, su sria. de conformidad aprobo el dho nombramto. y se mando llamar, para otorgar los poderes $p^{a}$ estas causas, para el miercoles seis del corrte. y para entonces se traigan ordenados. Idem. Lib. 74, 1677-78, fol. 99, 1-X-1678.

15 ORTIZ DE ZÚÑIGA, Diego (1671): Anales eclesiásticos y seculares de la Muy Noble y Muy Leal ciudad de Sevilla. Madrid. Imp. Real. 1796, t. III, pág. 398; reed. Sevilla. Guadalquivir eds. 1988.

${ }^{16}$ Es el testimonio de Ali Neyar "moro de nazión andaluz", vecino de Tetuán, que informó de noviembre de 1675 . Idem. Fol. 69v., testigo $3^{\circ}$. ACS. VIII. Leg. 44 (3). Informaciones del v. Siervo de Dios Fernando de Contreras. 1676. Fols. 225-246. Aue Maria, ssma. Breue derrottero del biaxe q yo Juan Mariño de Crestelo Hize a la Barbaria por horden y Mandatto de los Illmos. Señores diputtados en la caussa del Sanctto Pe. Fernando de Conttreras, sobre solicittar notiçias suyas en que Refiero algunas cossas partticulares Acaezidas en dicho biaxe, dignas de sauerse Para Mayor honra i gloria de Nuestro Señor y del Sanctto y Grandeza del Illmo. y Rmo. Señor dean y Cauildo de esta Sanctta Igleçia Por la que goza en thenos tal hijo. Año de 1676. 


\section{Fernando Quiles}

la pista de sus andanzas. Realizó una búsqueda sistemática por numerosas bibliotecas donde pudiera haber textos alusivos, es el caso de la del marqués del Carpio, en Madrid, con cuyo encargado, don Andrés Rodríguez de Brizuelas, trató en $1673^{17}$. En Sevilla acudió a diversos archivos particulares, como el que llaman del P. Pereira en col. de s. Hermengildo, o la librería del duque de Alcalá ${ }^{18}$.

\section{BUSCANDO LA “VERA EFFIGIE".}

Para la Catedral el Venerable Padre era uno de sus santos. Había sido sabiamente integrado en sus bienes inmateriales al dársele entierro en su trascoro, formando parte de su memoria histórica. Al considerarlo patrimonio particular suyo es lógico que luchara por acrecentar su fama y categoría al convertirlo en santo. De ahí que fueran los capitulares quienes condujeran el proceso de canonización y sostuvieran el gasto que ocasionó. Hicieron lo mismo con el rey Fernando III de cuya figura también se habían apropiado.

Una apología creíble de las virtudes de Contreras llevaría aparejada la formalización de la imagen real del hombre. En la corte pontificia se demandó la plasmación de esta realidad física. De manera que la búsqueda de esa efigie verdadera (vera effigie) fue una tarea asumida por Loaysa y resuelta satisfactoriamente.

Don Juan de Loaysa supo de la existencia de varios retratos auténticos de Contreras. Uno perteneció al noble tarifeño, don Fernando de Noroña, que lo hizo pintar por el patronímico, conservándolo en la capilla privada de su palacio hasta que su nieto don Alonso abandonara la plaza. Era de dos a tres quartas de quantidad pintada la cara y manos con su baculo en una y un Libro en otra ${ }^{19}$. De él se perdió todo rastro con el levantamiento del palacio de Tarifa, haciéndose eco de ello el emisario de Loaysa, Francisco L. Alejandro Matafranca, que en su camino al Magreb había recalado en la ciudad señorial ${ }^{20}$.

\footnotetext{
${ }^{17}$ Don Andrés Rodríguez de Brizuela diría que en la biblioteca de su señor, el marqués del Carpio, sólo había uno o dos libros de Francisco Pacheco, pero no se acuerda haberlos visto con retratos. ACS. VIII. Varios. Leg. 45 (4). Fol. 32r; Madrid, 14-VII-1673.

18 Además recibió el apoyo de Bartolomé Navarro, Diego de Zuñiga, Fernando de la Sal, Juan Bernal, el contador Marnuel Fernández Pardo y Diego de Góngora, entre otros. ACS. VIII. Leg. 46 (5). Fol. 532. 19 ACS. Leg. 45 (4). 112. Tarifa, 19-VII-1685.

20 Don Francisco Luis Alexandro Matafranca escribiría, desde Tarifa, a don Juan de Loaysa, el 19 de julio de 1685: Habla del Retrato del V. Pe. [Al margen]. Sr. Recibo vna de vmd. de tres de julio y en ella me insta la Breuedad de la diligençia en el negocio no esta sr. Lo [¿no?] tardo de my parte, sino en las pocas fuercas que estos Señores tienen para los negocios como lo tengo referido en respuesta de vna que llegara a manos de Vmd; en lo que aora me pide Vmd. aserca del Retrato del Venerable sto. fernando de Contreras, digo, Lo hiço pintar el Duque Dn. fernando de loroña a imitaçion de su nombre y estuuo en palaçio en su Capilla asta el tiempo, que su nieto Dn. Alonço de loroña gouerno (que este sr. Duque me falto por poner la vez passada) aquella plaça q fue el ultimo duque en el gouierno, ese fue el q en su ropa lleuo el quadrito, q segun me lo conto mi abuelo era de dos a tres quartas de quantidad pintada la cara y manos con su baculo en una y un Libro en otra; decir los años en ese particular es nececario ocurrir a Jorge Seco que es un Libro ( $q$ asi se intitula) donde estan los gouiernos y los años que gouernaron los Duques= en lo que Vmd me diçe escriua
} 
Frustrada esta posibilidad de encontrar la vera effigie de Contreras hubo de seguirse en otras direcciones. Una de ellas entre los descendientes de doña Teresa de Zúñiga y Guzmán (+1565), duquesa de Béjar, a la que el sacerdote había servido como capellán y del que tuvo dos retratos en su palacio de Villamanrique, uno de ellos de cuerpo entero ${ }^{21}$. Loaysa contactó con una tataranieta, doña María Guadalupe Alencastre, duquesa de Aveiro y Maqueda y esposa de don Manuel Ponce de León, $\mathrm{V}$ duque de Arcos, que no le pudo proporcionar los datos que buscaba, aunque convino con ella en la necesidad de intercambiar cualquier tipo de información ${ }^{22}$.

Y al fin Loaysa localizó un retrato auténtico de Contreras, del que se apropió y utilizó como modelo para su programa de ensalzamiento del personaje. La historia de este cuadro es poco clara y está salpicada de incógnitas de imposible resolución. Se dice que fue pintado por Luis de Vargas en 1542, con el lógico fin de permanecer en la Catedral. Este hecho no ha podido ser confirmado de manera fehaciente. Lo cierto es que al cabo de los años aparece entre los bienes de Bartolomé Herrera el Rubio, hermano de Herrera el Viejo. Tras su muerte, ésta y otras pinturas fueron adquiridas por el jurado José Bellero, para quien era un tesoro porque no auia otra. Finalmente acabó en poder de don Juan de Loaysa por cesión de los herederos del último propietario, su mujer María de Urbina y su hijo, también José Bellero. Esto último ocurrió el 28 de noviembre de 1672, a partir de entonces la historia se hace confusa $^{23}$. En esencia, el cuadro fue el referente básico de una nueva imaginería que se difundió con el progreso de la causa. Fue versionado sucesivas veces, aunque todas

\footnotetext{
a seupta es cosa cansada, por q son pocos los q ai q me lleuen ocho años, y luego son muy enteresados= faltome por poner q la dha $M^{a}$ de la Cruz fue muge de Ant ${ }^{\circ}$ Curado... ACS. VIII. Leg. 45 (4). Fol. 112. ${ }_{21}$ Doña Teresa de Zúñiga y Guzmán, duquesa de Béjar y marquesa de Ayamonte y Gibraleón, la gran duquesa, murió el 25 de noviembre de 1565 , en sus casas de la plaza de Regina; y fue enterrada en el convento de Regina. Esta señora se dice en la relacion de la vida del Pe. Contreras q imprimio el abad Gordillo q fue vna de las q se hallaron en Seva. a la muerte del siervo de Dios y q por sus manos le amortajó, están dos retratos suyos en el Palacio q tienen los Marqses. de Villamarq. en su lugar de $V^{a}$. manrique y en el mayor q es de cuerpo entero dice: D. Theresa de Zuñiga y Guzman gran duquesa de Bejar, fundadora del mayorazgo de $V^{a}$ manrique murio año de $1565 \mathrm{en} \mathrm{sev}^{a}$. y se entero en Regina q la dicha señora fundo...ACS. VIII. Leg. 45 (4). Fol. 254r.

22 A la duquesa: Lleua a V. Exc ${ }^{a}$ la Vera Effigie de su sto. Capellan $F^{o}$. de Contreras el sr. d. $g^{o}$. de arde. y Gan. arc. de esta s. ig a qn. he pedido la ponga en mano de $V$. Exc ${ }^{a}$. no ha sido posible remitirla antes por la dilacion del abridor yo quisiera q fuera de el mejor de Flandes. Aora ha venido (ACS. VIII. Leg. 46 (5). Fol. 33r). Muy deseado tenia saber ya q el retrato del Santo Pe. Contreras quedaua en mano de $V E$. como es seruida de participarme, y no es y casi me alegro auiendose aca descub $b^{\circ}$. Todo mucho $q$ en torrijos se dexen de hallar memas. pues con mui poca, o ninguna diliga. se sacó en dias pasados por mano de D. Gaspar de Ribadeneira can . de toledo la mem ${ }^{a}$. que va con esta, y aca se descubrio en vn libro antiguo, escrito de mano de Argote de Molina contemporanea q alcançó al Pe. Contreras el otro capitulo q vno y otro remito a $V$. Exc ${ }^{a} p^{a}$ que... (Idem. Fol. 34r. 24-IX-1675). A cuya mano remitiré una efigie suya en acabando de abrir la lamina, donde inferirá $V$. exc ${ }^{a}$. aun por el retrato lo heroico de ese gran varon (Idem. Fol. 35). De la duquesa: Doi a em. muchas gracias por el retrato del Santo Pe. con que me he alegrado infinito y con las buenas noticias de lo que se ha sabido de Argel... (Idem. Fol. 38. 20 ?-IX-75). Carta de Loayssa a la duquesa. Exma. Sra. Mui deseado tenia saber ya que el retrato del $S$. Padre Contreras quedaua en mano de VE. como es seruida de participarme. y dudo que en torrijos se dexen de hallar memorias pues auiendose descubierto aca en vn libro antiguo escrito de mano de Argote de Molina... (Idem. Fol. 39. 24-IX-76).

${ }_{23}$ ACS. VIII, Leg. 45 (4). Fols. 174v-175r. A esta cuestión me refiero en un artículo que tengo en prensa.
} 


\section{Fernando Quiles}

derivan de una primera copia efectuada por Murillo. De ella se sirvió Cornelio Schut para crear la estampa, que fue grabada por Martin Bouche, en Amberes. Esta versión estaba enriquecida por los símbolos del ministerio de Contreras, coincidentes con la idea que habían concebido los promotores:

pintura de cuerpo entero puede ser en la forma del Original con el manto negro de paño basto abierto por los lados, con la sobrepelliz llana y humilde como dicen los testigos, el Baculo en la mano o la diciplina, aludiendo a la gde. q se dio qdo. el obispado y a los pies todas las insignias de Mitra Pontifical Baculo pastoral anillo y demas insignias de Obispo. como despreciandolas o hollandolas y las insginias de Abad mas particulares $q$ ay hollandolas tambien. $y$ si pareciere niños caustivos y mucha gente cautiva a longes. por lo de redentor de cautiuos o entregando a el Baculo a los Moros q recibiran con reuerencia dandole al $s^{o}$ xptianos cautiuos ${ }^{24}$.

Idéntica es la lámina dibujada por Lucas Valdés y grabada por J. Mulder, que guarnece el panegírico oficial, la Vida del siervo de Dios y ejemplar sacerdote, escrito por el jesuita Gabriel Aranda. El libro fue impreso por Tomás López de Haro, a costa del propio Loaysa, entre 1689 y $1693^{25}$. El manuscrito obtuvo la aprobación del canónigo, al contrario de lo que ocurrió con otro texto escrito por el pintor Francisco Pérez de Pineda, como se desprende del tono doliente con que éste se expresaría en las décimas que le dedicara:

Conosco en vuestro saber, / Señor, que en mi manuscripto / haueis hallado delicto, / pues lo quereis recoger: / y aunque hazer desvanecer / vuestra alabanza al autor, / diziendo que es lo mejor: / ya segun lo que estoy viendo / Señor Don Juan, yo no entiendo / este linaje de amor. / Si algun fracaso se teme, / salga a luz a quien lo juzga, / si es bueno, para que luzga, / si es malo, para que se queme: / sed

\footnotetext{
24 ACS. VIII, Leg. 45 (4). Fol. 182r.

${ }^{25}$ Idem. VIII, Leg. 45 (4). Fol. 386. Fechas del contrato y de la carta de pago, respectivamente. Esta última dice así: SEPan qtos. esta Carta vieren como Yo Thomas Lopez de Haro impresor de libros Vez ${ }^{\circ}$. desta Ciud. de Seu.., otorgo y conosco que doy carta de pago al sor. Dn. Juan de Loayza canonigo en la sta. Yglessia desta Ciud. y vezino della de tres mill ochocientos y veinte y cinco Rs. de moneda de Vellon que son por resto y finiquito de la cantidad que a importado la impression del libro de la Vida del Venerable Sieruo de Dios Pe. ferndo. de Contreras q yo e impreso en que a entrado el costo de la lamina y estampas, Pliegos que se hizieron demas segun el concierto q conmigo se hizo por dho. sor. Don Juan de Loaysa enquadernaciones lizencias y Pliegos del indize y todo lo demas que corrio de mi cargo y obligacion Perteneciente al dho. libro cuya impression y libro a costeado de su propio caudal dho. ssor. Canonigo Don Juan de Loayza por el afecto que tiene a dho Sieruo de Dios..."10-1-1693. Ante Sebastián de Sta. María. Al margen: "La impression toda del Libro con estampas costó todo 12. raeles..." En el expediente hay una copia coloreada y firmada por "D. Lucs de Valdes J. Muldes Fecit.
} 
El venerable Fernando Contreras, un santo para la catedral de Sevilla

vos el timon, o leme [sic], / que desmintiendo riberas, / ynvestigueis las esferas; / conque quitandome enojos, / Señor Don Juan de mis ojos I diré, como de antes eras. I Si vuestro discurso anda / mirando humanos respectos, I por lo que mira a conceptos, / no está en casa Juan de Aranda: I no os hagais tan a la vanda, / que tan domestica guerra, /lo mugeril la destierra, / diciendo á tanto penar; / Don Juan se quiere embarcar, / Las Damas diçen que yerra. / En pleito que es tan sin arte, / en que quedo mejorado, / pido que me deis traslado, / si me conoceis por parte: / mas, si avista se reparte, / y en fabor setençia os dan, / saldre del penoso afan, / y mas, si dize el Juez: / tiene razon Doña Ynes, I dele la mano Don Juan².

Sin duda, el cultivado Loaysa no supo disimular la pobre impresión que le causaron las 99 octavas escritas por el discreto escritor. En ello coincidiría con el parecer de Ceán Bermúdez que tachó a Pérez de Pineda de mal pintor y peor poeta.

\section{EL ARTE DEL REGALO, EL ARTE REGALADO}

Es un hecho que para activar el proceso de creación de un santo, lo idóneo es mostrarlo como tal o al menos crearle el halo de bienaventurado, con una bien trabajada y acrisolada imagen. De ahí la insistencia de Loaysa por recuperar esa vera effigie que conquistara los corazones de los fieles y les moviera a devoción. Pero no todo se reducía a presentar el retrato auténtico en lugar público para contemplación del vulgo, era preciso introducirlo en los hogares, con un bien medido flujo de estampas.

Pero no se agota en este nivel expresivo el sentido de la imagen. Todo lo contrario, el éxito de la misma se producirá si logra cautivar al tribunal que iba a juzgar la importancia del personaje. Como la canonización se substanciaba en Roma, ante la Congregación de Ritos, había que destacar a un agente con las buenas cualidades del canónigo don Bernardo Gallo, diplomático y sumamente perspicaz, que ya se había estrenado en estas lides con el proceso de San Fernando. Había que ser cautos y proceder de acuerdo a un protocolo, en el que abiertamente se piden regalos en forma de pinturas:

Costumbre es de esta Corte, luego que se introduce una Caussa, en la Congregazon. dar quadros, y Pinturas, del pretendiente, al Promotor, Secretario, y Procurador y todos tres las piden, y desean.

${ }^{26}$ ACS. VIII, 56 (15). 


\section{Fernando Quiles}

Suppco. a VS. Illm ${ }^{a}$ vea que me manda en esto, para que con su orden, yo proceda mas conforme a su gusto, e intencion. Espero tabmien me mde. todo lo demas, en que quisiere le sirua ${ }^{27}$.

En esta costumbre, que supongo muy arraigada dentro de la corte pontificia, está el origen de un fecundo trasiego de obras e ideas artísticas. Tanto en una dirección como en otra. Pues, si bien hay pinturas encargadas a artistas locales y enviadas a Roma, las hay que siguen el camino inverso. En el caso que nos ocupa el agente catedralicio pide a su interlocutor sevillano el patrón de trabajo, un modelo para las pinturas que habría de encargar en la ciudad italiana:

Tomando Vs. Illma. resoluzon. de que se den quadros, se serbira se me imbie, alg $^{a}$ ymagen de este santo, hauiendo por alla, $p^{a}$. ajustar los quadros ${ }^{28}$.

El 12 de septiembre de 1673 Loaysa comunica a Gallo que está en ello, pero que espera que Murillo haga el retrato ${ }^{29}$ :

Pe. D. Bern ${ }^{\circ}$ Gallo. Seu ${ }^{a}$ y sete. 12 de 1673.

Aunq este correo no hemos tenido carta de V. m. q sera por la nouedad de la causa del s. Rey, de cuyo buen suceso le damos el parabien, escreuimos a V. m. pe. q sepa q no van oi las cartas y poder de $n$. $s^{o}$. Contreras porq el sr. D. Juan de texada aun no nos ha remitido la de la Reina $n$. $s^{a}$. que aguardamos el correo siguiente por remitirt tod embiarlo todo en vn pliego quanto a la $V^{a}$ Effigies, nos ha dicho Bme. murillo q hara vna pintada y acabada en lienço, q sirua de Original, de donde se copien allá las otras, que quisieramos fuera todo esto con breuedad mas no es posible por auer partido de Cadiz la Semana pasada el Combos con q es preciso dilatarlo hasta tener ocasion a proposito para remitirla en vna caxa de madera, o como mejor y mas seguramente pareciere. V. m. no nos dexe de escreuir q en caa carta aguardamos la noticia de auer hallado los papeles $q$ se buscan... ${ }^{30}$.

Y dos semanas más tarde la obra está comenzada:

Quanto a la vera effigies, se va prosiguiendo, como diximos a $V$. $m$. en la antecedente, para remitirla con toda seguridad ${ }^{31}$.

\footnotetext{
27 Roma, 29-VII-1673. ACS. VIII, 47 (6), fol. 30.

28 Idem, postdata.

29 ACS. VIII, 47 (6). Fol. 34. A don Bernardo Gallo, en Sevilla, 29-VII-73.

${ }^{30}$ Idem. Fol. 35. 12-IX-1673, Sevilla

31 Idem. Fol. 36v. A d. Bdo. Gallo, 26-IX.
} 
En mayo del año siguiente aún aguarda Gallo que le llegue el cuadro. En Roma le aprietan para que acelere las gestiones, inquietud que transmite al deán y cabildo:

Los ministros de la Sagrada Congregon. de Ritus me aprietan por los quadros que les tocan de la causas del sto. Contreras y de la Sta. Me. y me diçen q es razon que se los de, supuesto que he alcanzado lo que he querido, y assi me pareze conueniente, por no disgustarlos, el que VS.I. me enuie la efigies de dhos sanctos, para que se hagan los dhos. quadros, y los de aquienes van de costumbre que es quanto se me offreze... ${ }^{32}$. Dorotea:

Por fin en junio de ese mismo año está acabada la pintura, con la de la Madre

$Y$ en qto a las efigies de los dos siervos de Dios, decimos q ya estan acabadas y mui a nr. gusto, pero no ai aun ocasion de enbiarlas, $y$ assi q las aya las embiaremos q por ser grandes y desear $q$ vayan con toda seguridad no lo hemos hecho hasta aora no se ofrece otra $\cos ^{33}$.

En diciembre el padre Gallo justifica al cabildo el interés de abrir la lámina de Fernando Contreras por los frutos que se pueden cosechar entre los fieles, al suscitar en ellos la devoción hacia su figura y así facilitar su contribución económica al proceso ${ }^{34}$.

Murillo entrega su copia al Cabildo, que la acepta y la expone en la Sacristía mayor. Al cabo de una década, en 1688, Loaysa regala a la Catedral la vera effigie atribuida a Vargas, que había conservado. Los capitulares la destinan a la misma estancia, tal como hoy puede observarse. En este punto cabe preguntarse por la versión de Murillo que ha desaparecido ${ }^{35}$. En todo caso el empeño puesto por

\footnotetext{
32 Idem. Fol. 100r-v. D. Bernardo Gallo al deán y c. en su dip. de los ssres. Contreras y Fac. Dorotea.
Roma, 19-V-1674.

${ }_{34}$ Idem. Fol. 100v. Borrador. Al pe. Gallo, 19-VI-74.

${ }^{34}$ Idem. Fol. 133v. 29-XII-74. Gallo al Deán y Cabildo, en su diputación de ambos personajes: y $q$ se acauara de imprimir todo, y en la dha. instrucccion, no esta el q sea nesessario, el q se habra la lamina de la vera efigie de este sieruo de Dios, porq. es gasto q se podria haser de menos, sino es q VSIllma. la mande hacer con animo, de q en esta Ciudad, se le cobre deuocion, por los ciudadanos, los qules. para obra tan pia contribuiran con limosnas para el proesseguimiento de esta cussa, y para esta Ciudad, por aora, no es de prouecho, porq ay muchas caussas de Santos, q stan para Beatificarse y canonizarse, y no tienen la vidas impressas con las laminas de la veras efigies, las quales siruen solamente, para ponerse quando se imprimen algunas en los libros, juntamente con la efigies de los Cardles. Poniente de la caussas

de Santos, q estan inmmediatos para beatificarse o canonizarse, y esta es la costumbre q aqui ay.
35 Sobre este asunto me extiendo en un artículo que está en prensa.
} 


\section{Fernando Quiles}

promotores y artistas acabó en las estampas abiertas por Bouche con dibujo de Schut efectuado siguiendo el modelo apenas concluido. En cierto modo fueron satisfechas las expectativas levantadas por dicha obra. Esta circunstancia nos permitiría fechar el grabado, situándolo en torno a 1674. Repite la efigie del lienzo, salta a la vista la identidad, incluso el texto apócrifo de la tela está repetido al filo del tondo grabado: V. EFFIGIES V. SERVI DEI FERDINANDI D. CONTRERAS SACERDOTIS HISPALENSIS CAPTIVORVM. M.D.XLVIII. AET. LXXII.

Pero como el proceso sigue su curso sin que se alcance el resultado esperado, éstas no serán las únicas imágenes que se producirán. Tal vez sí sean las de mayor calidad, aunque dado el sentido expresivo que tienen es comprensible que acabaran siendo suplantadas con los años y el cambio de los gustos estéticos. Nace así una nueva versión en el curso del nuevo siglo, más acorde con otra sensibilidad más expansiva y emotiva. Pese al evidente fracaso de los promotores del proceso, está asegurada su continuidad, una vez ganado el apoyo de importantes sectores sociales. En su conjunto la ciudadanía había adoptado a Contreras como santo, como se verá en los años treinta del siglo XVIII, cuando sea patente que la curia pontifica va por detrás de la sociedad sevillana. Ante la incongruencia de la situación don Luis de Salcedo, arzobispo, reconduce el proceso. De esta época datan las Letras Remisoriales y Compulsoriales de la Sagrada Congregación de Ritos ${ }^{36}$. En 1733 se halla en Roma, como intermediario del Cabildo sevillano don Juan José de Zamora ${ }^{37}$.

Ni con todo su ímpetu e ilusión logró Salcedo progresar, aunque le preparó el terreno a su sucesor, el ilustre cardenal Francisco Solís. Como hombre de su tiempo, influyente y bien conocido por la corte romana, revitalizó el proceso, aunque sin llegar a rematarlo convenientemente. Procede entonces cambiar el retrato por otro ejecutado por un afamado pintor sevillano que había completado su formación en Roma, Juan Preciado de la Vega. Este artista había iniciado sus estudios en el taller del pintor local Domingo Martínez, desprendiéndose de esa carga barroca por la incidencia de la academia romana, de ahí que estuviera a la altura de las circunstancias, al gusto de la corte pontificia. El autor de la Arcadia Pictórica atendió el encargo con dos lienzos, pintados en 1771, para regalar al Prefecto de Ritos, el cardenal Marefoschi y al Promotor del proceso $^{38}$.

\footnotetext{
${ }^{36}$ ACS. VIII. Leg. 48. Autos de la causa de beatificación y canonización de Contreras. En virtud de letras remisoriales de la Sagrada Congregación de Ritos expedidas 24-VII-1731, ante Salcedo. y los señores Gabriel de Torres y José Manuel de Céspedes y Juan Cornejo y Joaquín de la Pradilla, a petición de Diego Antonio del Campo.

${ }^{37}$ En Roma se encuentra en 1733 Juan José de Zamora, intermediario de la Iglesia sevillana. En esta semana passda rezeui de D. Ant ${ }^{\circ}$ Cabello, el libro de la vida de nro. ve. con los compendios y retratos. ACS. VIII, 56 (15). Roma, 17-I-1733.

38 Ytem por dos quadros del ve. Contreras el uno en lienzo de Emperador para darse al nuevo Pref ${ }^{\circ}$ de Ritos al Cardl. Marefoschi, y el otro en lienzo de 4 palmos para el nuevo Promotor en todo... 55 [escudos] 50 pagados al Pintor, como de su recivo que se remite. ACS. VIII. Leg. 56 (15). S. fol. Nota de los gastos que se hacen por el Illmo Cabildo de Sevilla, en la causa del Vene. Fernano de Contreras en la Congregn. de Ritos. 1771.
} 
En 1778 comunicaba don Ignacio de Aguirre a don Martín Alberto Carvajal, agente del cabildo en Roma, que los cuadros, copias del retrato original de Contreras, estaban acabados y prestos para serles entregados. Previamente le habían sido encargados a Preciado dos dibujos coloreados en tela hechos para ser grabados, distintos por tanto de los dos lienzos:

\section{Roma 19 de Agosto de 1778.}

Mui sr. mio y de mi maor. estimacion. En satisfacion de la apreciable de VS. de 18 del pasado solo deuo decir que la copia del retrato original del mro. Vene. Contreras esta concluida desde el dia 8 del corriente, y que Castel Ruiz aguarda qe se proporcione embarcacion para Genova a fin de remitir a VS. los consavidos quadros.

Excusado me parece repetir que el difunto Lasalde encargó a Preciado por quta. de la Causa los dos dibujos que pagué, pues creo que por mis antecedentes Vs. se abra hecho cargo de que Yo Justifiqué con razon este pensamiento, y de que es cosa mui distinta del quadro ó quadros los dos pequeños dibujos para sacar las estampas del Vene., hechos al oleo en una tela del tamaño de un pliego, grande el uno, $y$ menor el otro. intermision:...

Me asegura Costanzi que travaja // en la Causa sin

Ignacio de Aguirre al sr. d. Martin Alberto Carbajal ${ }^{39}$.

Poco después, en 1784, y, en lógica sucesión, sale del taller del librero romano Lorenzo Cupis una nueva edición de las estampas de Contreras, con la imagen del Venerable grabada por don Demetrio Dragón, repitiéndose edición en 178740. Carvajal mediaba en el encargo.

A principios del siglo XIX agoniza el proceso, aunque aún hay intentos de avivarlo con la edición de más estampas, tiradas por Pedro de Moya en $1805^{41}$.

\footnotetext{
39 Idem.

${ }^{40}$ Idem. Leg. 55 (14). Cuenta de 1784, desde 30-VII. Lorenzo de Cupis librero. Al Gravador dn. Demetrio Dragon por haver gravado la Imagen del Ve. Contreras incluso el gasto de la Lamina, y consta de su reciuo, 20 bayocos. Recibo de 350r. por imprimir mil estampas del venerable padre y tirar otras quinientas en cuartilla de papel marca mayor, a 30 reales las cien y 20 por la impresión de mil en medio pliego de media marquiella, 9-IX-1805. Fdo. Pedro de Moya.

${ }^{41}$ Idem.
} 


\section{Fernando Quiles}



1.- El venerable D. Fernando de Contreras 